$\checkmark$ mirror and sending the signal to a few sensors, it will capture instantaneous views of a 185-kilometre swathe of Earth, using some 7,000 sensors for each bandwidth. The result is more data from each location and better image quality. "The data are much more sensitive to change across the landscape and over time," says Jim Irons, project scientist for the mission at NASA's Goddard Space Flight Center in Greenbelt, Maryland. "Maybe we will be able to better differentiate corn from sorghum, for example, or maple trees from oak trees."

The spacecraft will also be the first in the Landsat series to collect data in an 'ultrablue' band, particularly useful for studying oceans and atmospheric aerosols. Another new data stream will be a shortwave infrared band that is sensitive to cirrus clouds, which are powerful players in Earth's climate.

Landsat has endured major changes in ideology and organization during its lifetime, notably in the 1980s and 1990s, when Congress gave control of the satellites and all data to a private company. Images sold for several thousand dollars each, limiting analysis to an elite corps of scientists. The government regained control in 2001, however, and from 2008 the US Geological Survey, which oversees the data, opened up the archive as a free global resource. Access exploded. Whereas the agency once sold around 15,000 images a year, annual downloads now average about 3 million.

"It provided for data democracy," says Mike Wulder, a research scientist at the Canadian Forest Service in Victoria and a member of the Landsat science advisory team. "Landsat really is a global resource."

The data helped to spark a digital revolution among remote-sensing specialists, who have developed tools to exploit massive computing resources and stitch together high-resolution records of global change over time and space. Other space-borne imagers, such as the Moderate Resolution Imaging Spectroradiometer (MODIS) on NASA's Terra and Aqua satellites, can take snapshots of larger areas at a single pass, but with much lower resolutions.

With Landsat, "we can get the detail and the enormous geographic coverage", says Asner. "This alone puts Landsat at the very forefront in land-cover and land-use change monitoring."

Landsat 8 is scheduled to begin operations 90 days after entering orbit, although the first images could arrive within three or four weeks. The satellite might not live as long as its predecessor, which NASA engineers have put forward as a candidate to Guinness World Records, but Irons believes that Landsat 8 will make its own mark. "I do not think it hyperbole to suggest that all seven billion of us will benefit from the Landsat continuity mission."

NUCLEAR ENERGY

\title{
Quake fears rise at Japan's reactors
}

\section{Commissioners say that geological faults make some reactors too dangerous to restart.}

\section{BY DAVID CYRANOSKI}

$\mathrm{P}$ lans to restart some of Japan's 50 nuclear reactors, which have been idle since the Fukushima Daiichi disaster in March 2011, have hit an obstacle - and his name is Kunihiko Shimazaki. Buoyed by a new cabinet keen on nuclear power, the nuclear industry wants to get the plants back online to meet the country's energy demands. But before it can do so, Shimazaki and a group of 16 other geophysicists working for the country's Nuclear Regulation Authority (NRA) must confirm the industry's claims that the plants do not face a serious earthquake threat.

To judge by his initial reports, Shimazaki won't accept the claims lightly. On 28 January, Shimazaki, an NRA commissioner who warned in 2004 that Fukushima's coast was more vulnerable to tsunamis than regulators had claimed, angered proponents of nuclear energy by reporting his group's conclusion that there is probably an active fault under the Tsuruga nuclear plant, which was due to restart. If, as expected, the NRA endorses that finding, the plant won't be allowed to operate.

But the team's evaluations have been questioned, and not just by the nuclear industry. Seismologists dispute whether the faults that Shimazaki's researchers are finding meet the NRA's definition of 'active', meaning that they have generated an earthquake in the past 120,000 years or so. In some cases, say the critics, the fractures are not dangerous and some may not even be faults at all.

"They are being overly cautious just to avoid criticism," says Koji Okumura, a palaeoseismologist at Hiroshima University who was on an expert subcommittee of the cabinet's Nuclear Safety Commission until it was replaced by the NRA in September 2012. "They think they're like Superman coming in to save us from the bad guys."

Shimazaki's team is evaluating five plants, comprising 12 reactors in total, plus the shut-

$\rightarrow$ NATURE.COM For more on Japan's earthquake and nuclear crisis see: nature.com/japanquake tered Monju experimental fast breeder reactor (see 'Finding faults'). Four of the five plants are due to restart; at the fifth, two of the four reactors are already running. What the team is finding is often at odds with the industry's assessment.

The Tsuruga plant's reactors, for example, are 250 metres from a known fault. Excavations by the plant's owner, the Japan Atomic Power Company, showed that the ground had shifted across the fault, suggesting that the fault had been active. But the company's experts had concluded that the movement had happened before the 120,000-year threshold.

When Shimazaki's experts examined the company's trench, they found signs of more recent movement, and evidence that an extension of the fault runs directly beneath one of the reactors. "If you look at the displacement and slant, it looks like it's a continuation" of a fracture running under the reactor, he says.

Problems also turned up in a survey by the Kansai Electric Power Company (KEPCO) of its Oi plant, which houses Japan's only two running reactors. The plant is bisected by a fault, which KEPCO says is inactive. But Shimazaki says that crucial data from the original trench dug by KEPCO's researchers are missing. And in December, Shimazaki announced that his group had found an active fault near the Higashidori plant, at which one reactor is idle, one is under construction and two more are planned. A full report is expected soon, but the Tohoku Electric Power Company, which operates the plant, says that it will produce data proving that the faults are not active.

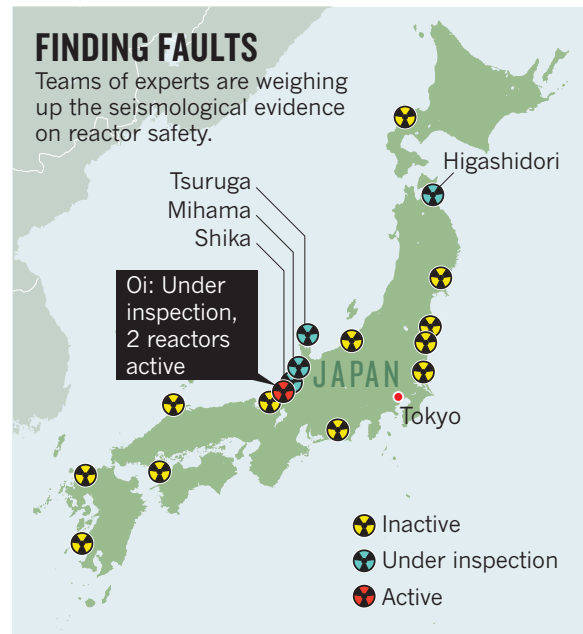


Meanwhile, surveys at the other two plants and the Monju reactor are set to begin this year. But critics are questioning the group's methods.

Okumura says that some of what Shimazaki's experts are citing as active faults could well be the result of landslides. He says the group lacks specialists on rocks and sediments - a limitation that the NRA says it has addressed by consulting the relevant experts.
Others are concerned that the group has been too quick to conclude that the fractures they have identified are dangerous. "There are fractures everywhere you look," says Haruo Yamazaki, a seismotectonics researcher at Tokyo Metropolitan University. He says the debate should focus on what, if any, damage the reactors would suffer if the faults moved.

Shimazaki says that the NRA will weigh up the plants' vulnerability to earthquake damage as it evaluates the seismology reports. But the plants will face more hurdles if regulations being drafted by the NRA become law without changes. Due to take effect in July, new requirements for vents and radiation filters could mean that the Oi reactors would have to be shut down immediately and others could not restart without modifications.

\section{Alert over South Korea toxic leaks}

\section{Government moves to tighten oversight after string of hydrogen fluoride accidents.}

\section{BY SOO BIN PARK IN GUMI, SOUTH KOREA}

$\mathrm{B}$ y mid-December, the chill winter winds had stripped South Korea's trees bare. But around the city of Gumi, about 280 kilometres south of Seoul, blighted branches still bore a shroud of brown, withered leaves - reminders of the chemical accident that shook the region some three months earlier. At the edges of arable fields, red placards waved in the breeze: "Contaminated by the hydrofluoric acid leak," they warned. "Not edible."

On 27 September 2012, about eight tonnes of highly toxic hydrogen fluoride (HF) gas, which dissolves in the moisture in air to form droplets of corrosive hydrofluoric acid, burst from the Hube Global chemical plant in Gumi. The leak killed five workers and injured at least 18 others, including plant employees and emergency personnel.

Thousands of local citizens say that inhaling the acid has damaged their health. Exposure to HF can trigger an irregular heartbeat and cause fluid buildup in the lungs, and the long-term health effects include chronic lung disease. The government has said that it will pay about 36.4 billion won (US\$33.4 million) in compensation to citizens and local businesses.

This may sound like a freak accident but it was not. On 15 January, about 2,500 litres of hydrofluoric acid escaped at a factory in Cheongju, injuring one person. And on 28 January, a worker died during a hydrofluoric acid leak at a Samsung Electronics computer-chip plant in Hwaseong. In the wake of the incidents, experts are raising questions about safety in the country's research-intensive chemical and microelectronics industries, and the government is investigating what went wrong.

"South Korea tends to focus on resolving accidents only when death occurs, but action to prevent such accidents is still severely lacking," says Lim Hyun-Sul, a researcher in preventive medicine at Dongguk University in Gyeongju. Lim, who has been treating patients for HF exposure since the 1990s, says that preparation is key. "Protocols must be pre-

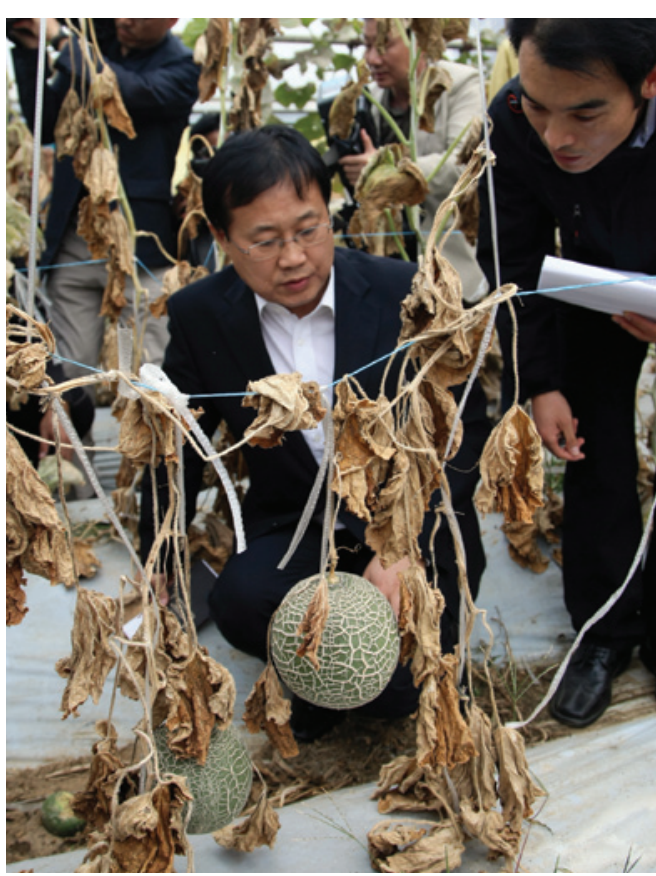

Government investigators survey the impact of a hydrogen fluoride leak.

pared thoroughly in advance, including education of factory workers, firefighters, medical doctors and public servants about the risks of toxic chemicals."

\section{HANDLE WITH CARE}

Hydrofluoric acid is commonly used by the electronics industry to etch patterns into silicon chips, and as South Korea has become one of the world's leading electronics exporters in recent years, annual consumption of HF has risen sharply. According to the Ministry of Environment, 26 businesses each handled around 10 tonnes of HF in 2001; by 2010, the number of these large-scale handlers had almost tripled, and in 2011, 545 companies were registered as producers or distributors of the gas.

A mistake by Hube Global workers may have caused the Gumi disaster. Surveillance-camera footage seen by Nature shows two workers attempting to connect a hose to a valve on top of a HF tank. Neither is wearing protective gear. Suddenly, white vapour gushes from the tank, engulfing the workers and killing them instantly. Prosecutors have indicted three Hube Global executives on suspicion of negligence resulting in death, citing the absence of proper safety equipment and a lax attitude to safety regulations.

The disaster was compounded by the regional government's response. "Both the immediate and the long-term response to the hydrofluoric acid release from the South Korean government seemed to be really chaotic and uncontrolled," says Neal Langerman, who runs the consulting company Advanced Chemical Safety, based in San Diego, California.

Some firefighters failed to use chemicalprotective clothing and self-contained breathing apparatus because they did not initially understand the threat posed by HF. Almost a day passed before they began using calcium hydroxide to neutralize the acid, which is standard procedure after such a leak.

Meanwhile, residents nearby were exposed to HF for about four hours before local authorities decided to evacuate them. The following day, they were told to return after investigators found no HF in the air. But thousands of residents soon complained of nausea, chest pains and rashes, suggesting that the all-clear had been sounded too early. Eleven days after the accident, the national government designated the area a 'special disaster zone', and residents began to leave again.

Evacuated residents finally returned 